\title{
Determinants of Rural Household Poverty: The Case of Sodo Zuria Woreda, Wolaita Zone, Southern Ethiopia
}

\author{
Habtamu Honja Shaga ${ }^{1 *}$, Tekle Leza Mega ${ }^{2}$, Marisennayya Senapathy ${ }^{3}$
}

\begin{abstract}
${ }^{1}$ Coffee, Tea and Spices Development and Marketing Directorate Director, Sodo Zuria Woreda, Agriculture and Natural Resource Development Office, Wolaita Zone, ETHIOPIA

${ }^{2}$ Vice President for Business and Development and Associate Professor, Department of Rural Development and Agricultural Extension, College of Agriculture, Wolaita Sodo University, ETHIOPIA

${ }^{3}$ Associate Professor, Department of Rural Development and Agricultural Extension, College of Agriculture, Wolaita Sodo University, ETHIOPIA

*Corresponding Author: habtamuhonja327@gmail.com
\end{abstract}

Citation: Shaga, H. H., Mega, T. L. and Senapathy, M. (2021). Determinants of Rural Household Poverty: The Case of Sodo Zuria Woreda, Wolaita Zone, Southern Ethiopia. European Journal of Sustainable Development Research, 5(2), em0157. https://doi.org/10.21601/ejosdr/10844

\section{ARTICLE INFO}

Received: 23 Sep. 2020

Accepted: 29 Jan. 2021

\begin{abstract}
Poverty is one of the central issues and the most far-reaching social matters on the planet. It has no geological limit. Along these lines, this examination has done to distinguish the determinants of the rural household poverty in Sodo Zuria Woreda of Wolaita Zone, Ethiopia. To accomplish this goal, 152 rural family units were chosen using a systematic random sampling technique following the corresponding method's likelihood. The primary and secondary data optional information just as quantitative and qualitative subjective details have been used. In this investigation, the Cost of Basic Needs approach has applied to determine the extent of the poverty line and Foster-Greer and Thorbecke Poverty Index has used to decide the degree of rural poverty. The aftereffect of the basic needs approach's cost shows that the investigation zone's poverty line was about 5348.073 Birr every year per adult equivalent consumption. Utilizing this poverty line as a benchmark, the investigation demonstrated that 39.47 per cent of the family units were poor. The headcount index, poverty gap and squared poverty gap indexes among poor people families are $0.3947,0.1035$ and 0.0427 . The Binary Logit Regression model's discoveries show eight significant variables at under $1 \%, 5 \%$ and $10 \%$ likelihood level among 15 factors. As needs are, the family size was a positive relationship with the rural family's poverty and measurably significant. In the interim, sex, age, educational level, land size, total livestock unit, use of technology and participation of saving have a tangible negative relationship with the rural household poverty and factually huge up to under $10 \%$ likelihood level. There is a need to reinforce the link between rural development and poverty reduction programs that consider old aged and female-headed families in mediations, limit populace size through integrated family planning and education obligations introduce appropriate livestock packages, and create awareness of the farmers for using new agricultural technologies.
\end{abstract}

Keywords: cost of basic needs, determinants, extent, poverty, poverty line, food poverty, non-food poverty

\section{INTRODUCTION}

\section{Background of the Study}

Poverty is one of the significant trauma and the most some social problems on the planet. It has no geological limit. It has found every which way and corners (Borko, 2017). Notwithstanding uncommon world advances in science, innovation and riches creation, poverty in the entirety of its indications stays profound and dynamic. Poverty is multifaceted and has no single commonly acknowledged definition. In reality, it is multidimensional. Thus, writings on the idea of destitution show different understandings in monetary, social, political, institutional, ecological, and social settings (Lekobane, 2017).
Rural poverty represents about 63 per cent of around the world, arriving at 90 per cent in individual nations like Bangladesh and 65 and 90 per cent in Sub-Saharan Africa (IMF, 2010).

In the more significant part of the developing nations bigger populace are living in the country than urban; some 3.1 billion individuals, or 55 per cent of the all-out populace, live in rural zones out of this about 1.4billion individuals live on under US $\$ 1.25$ per day, and near 1 billion individuals experiencing hunger (Nakachew, 2018). In the vast majority of developing nations, the quantities of poor and hungry individuals are expanding. Around 70 per cent of the world's needy individuals (approximately one billion) are rural, and a massive extent of poor people and hungry among them are children and youth (Mohammed, 2017). 
Poverty in Ethiopia has profoundly related with the size and structure of the families, the educational level of the family unit head, the degree and degree of reliance inside the family, asset possession (especially ownership of Oxen in rural areas), the control of the family unit heads, fast populace development, significant medical issues, absence of foundation and great natural debasement. Consequently, recognizing what attributes are related to rural poverty can yield essential experiences for strategy creators (Borko, 2017).

The level and dissemination of poverty in Ethiopia are declining every now, and exceptional financial development has been watched. As indicated by the outcomes acquired from the 2010/11 Household Income, Consumption and Expenditure Survey and Welfare Monitoring Survey of the Central Statistical Agency (CSA,2011), around 39 per cent of the complete populace were under the poverty line, out of which 39 per cent in rural areas and 35 per cent in urban zones. While break report on the poverty examination study arranged by MoFED utilizing the 2015/16 HICES and WMS uncovers, the poverty line declined to 29 per cent (CSA, 2016).

Despite this all improvement, neediness as a rule and rustic destitution in incredibly still it isn't just ceaseless yet additionally profound. Along these lines, poverty is a significant compelling element among cultivating family units. Therefore, this examination centred around determinants of rural household poverty in Sodo Zuria District (Woreda) by including the most vital segment and financial factors.

\section{Statement of the Problem}

Poverty in Ethiopia is profound and endemic. The country's overall composition and influencing numerous sufferings and misery to the populace's most significant extent. It is the Government's high plan, benefactor's offices, NGOs, and different entertainers that have the motivation to diminish the level and alleviate the impact and its related effects on the prosperity of the individuals (Tiruneh, 2006).

Ethiopia is perhaps the most impoverished nation on the planet, with extremely low Human Development Indicators positioned 174th out of 188 countries (ADBG, 2015). Around 23 million Ethiopians live in conditions generously underneath the primary poverty line, and food insecurity stays a significant test. About $40 \%$ of children under five are undernourished and hindered (Nakachew, 2018).

As per CSA (2015), Population Census Projection out of the $18,276,012$ all-out populace of SNNPR around 89 per cent of the complete populaces lives in rural areas. The rate of rural poverty incidence in the district is higher than the urban regions, and still an enormous number of the rural population is underneath the poverty line.

Then again, Wolaita Zone is one of the main thickly populated zones in the SNNPR. It prompts a little normal farming area per rural family unit around 0.45 hectare, one of the primary sources for genuine and chronic poverty in the Zone (CSA, 2017).

According to Sodo Zuria Woreda Finance and Economic Development Office (2018), socio-economic data indicates that about 6303 households and 18,858 populations of the Woreda depend on the safety net program used relief and contingency aid. The Woreda faces different constraints, including the shortage of land and soil infertility, low agricultural productivity, vulnerable to rainfall shortages and variability, and their significant economic activity depends on rain-fed agriculture.

Many researchers conducted on poverty and its correlates in SNNPR in general and in Wolaita Zone in particular. Still, poverty is dynamic, and their determining factors vary from one place to another because different areas have different development options. The poverty situations of the study area have not focused much attention on the grass-root level. So, the problem triggers the researcher to focus on rural poverty research studies in Sodo Zuria Woreda's study area. Therefore, this Woreda has not yet been researched previously, and it needs the research to identify the determining factors of rural household poverty.

Therefore, the research's motive was to fill the skill and area gap in measuring poverty by identifying those determinants of rural poverty and suggest recommendations based on the findings. They become sound enough to plan on the poverty and targeting of policymakers in executing the study area.

\section{Objectives of the Study}

The investigation's overall goal was to evaluate the rustic family neediness determinants in the examination territory. The examination dependent on the accompanying explicit targets;

- to assess the status of rural poverty in the investigation territory,

- to distinguish the determinants of the rural household poverty in the investigation region.

\section{RESEARCH METHODOLOGY}

\section{Description of the Study Area}

The investigation has led in Wolaita Zone, Sodo Zuriya Woreda, one of the 16 Woredas in the Wolaita zone, SNNPR, Ethiopia. It is situated at $156 \mathrm{~km}$ southwest of the Hawassa town, Southern Regional State's capital and 330km from Addis Ababa.

As per the Sodo Zuriya Woreda Agriculture and Natural Resource Development Office (2018), the Woreda covers $38,040.8$ hectares of land and has two agro-ecological zones. In particular Highland/Dega 10\%/and Midland/Woynadega 90\%3/. Its height ranges from 1500-2950 meters above ocean level with a mean yearly temperature of 180c.

In view of the 2007 Census led by the (CSA), the total population of the Woreda is 184,125 of which 90,794 are men, and 93,331 are women. Population thickness of the Woreda is 502 for each square $\mathrm{Km}$; which is a lot higher than the regional thickness of 141 individuals $/ \mathrm{km} 2$ and the zonal thickness of 414 individuals $/ \mathrm{km} 2$. The average family size of the Woreda is five, which are equivalent to the Zonal and local normal of 5 (CSA, 2007). 
Table 1. Selection of the Kebeles and Sample size

\begin{tabular}{cccc}
\hline $\begin{array}{c}\text { Name of } \\
\text { Kebeles }\end{array}$ & $\begin{array}{c}\text { Total } \\
\text { population }\end{array}$ & $\begin{array}{c}\text { Total } \\
\text { Households }\end{array}$ & $\begin{array}{c}\text { Sample } \\
\text { Households }\end{array}$ \\
\hline Zala Shasha & 5533 & 1112 & 33 \\
\hline Gulgula & 3632 & 763 & 23 \\
\hline Wachiga Busha & 7905 & 1733 & 52 \\
\hline Waja Shoya & 2682 & 558 & 17 \\
\hline Kenefa Godera & 2992 & 902 & 27 \\
\hline Total & $\mathbf{2 2 7 4 4}$ & $\mathbf{5 0 6 8}$ & $\mathbf{1 5 2}$ \\
\hline
\end{tabular}

Source: Sodo Zuria Woreda Finance and Economic Development office, 2018

\section{Research Design}

The study used a cross-sectional study design, where data were collected at a single point in time using a survey method. The reason for choosing this design is because it is flexible and economic (Babbie, 1995). Besides, the subjects were tested once at the same time.

\section{Sampling Techniques and Sample Size Determination}

Multistage sampling procedures were applied to choose the sample respondents. Sodo Zuria woreda was selected by purposive sampling methods at the principal stage because of the researcher's past and current information and admittance to get information. In the subsequent stage, the Woreda was defined as dependent on agro-ecologic qualities like Dega (highland) and Woina Dega (midland). Thirdly, from complete 24 Kebeles found in the Woreda, one Kebele from Dega and four Kebeles from Woynedega was chosen using a simple random method. The chosen Kebeles were Zala Shasha, Gulgula, Wachiga Busha, Kenefa Godera and Waja Shoya. Finally, 152 example respondents were selected from five chose Kebeles by utilizing systematic random sampling methods based on the Probability Proportional to Size (PPS) (Table 1).

Sample size determination techniques were applied by using Yamaneh (1967) formula to decide the necessary size at a $92 \%$ confidence level, and level of precision $=8 \%$.

Likewise;

Though; $n=\frac{N}{1+N(e)^{2}}$ Whereas; $n=\frac{5068}{1+5068(0.08)^{2}}=152$

Where, $\mathrm{n}=$ is the sample size, $\mathrm{N}=$ is the population size (absolute individuals from households), and $\mathrm{e}=$ is the level of precision (margin error) 92\% degree of accuracy was checked.

Accordingly, 33, 23, 52, 17 and 27 households were selected randomly for the household survey from Zala Shasha, Gulgula, Wachiga Busha, Waja Shoya and Kenefa Godera kebeles, respectively.

\section{Data Types and Method of Data Collection}

Both qualitative (subjective) and quantitative information were gathered from primary and secondary sources. The primary data were collected through a household survey from the chose 152 sample respondents. Secondary data were accumulated from legitimate records, books, diaries, releases, magazines, measurable reports, sites, and unpublished materials.

All the quantitative information was gathered by utilizing Interview Schedule meeting plan from the sampled respondents, and qualitative (subjective) data was collected from non-sampled respondents such as Focus Group Discussion (FGDs) and Key Informant Interviews (KIIs).

\section{Strategy for Data Analysis}

The information was dissected by utilizing various techniques, for example, enlightening, FGT strategy and econometric models.

\section{Descriptive statistics}

For example, elucidating factual procedures, mean, rate, and standard deviation were utilized to distinguish financial factors in examining information. In particular, SPSS version 21 programming was used to break down all of the quantitative data gathered in the review.

Inferential insights were utilized to see the connection between theorized defining factors and ward factors; for example, t-test and chi-square test was used.

\section{Derivation of poverty line}

Cost of Basic Need approach (CBN): was utilized to decide the poverty line; it considers both the food and non-food prerequisites, is the most broadly used strategy for assessing the destitution line. It was more delegate, and the limit was steady with actual consumption across time, space and financial gatherings. This methodology is favoured because it is utilized to discover utilization essential to meet least means needs (NPC, 2017; World Bank, 2005).

The rundown proportion of the poverty line was made utilizing the most well-known ratio of destitution Foster, Greer and Thorbecke (FGT, 1984) classes of neediness measure. Encourage, Greer and Thorbecke level of destitution investigation was utilized to decide the extent of family units living beneath or more poverty line and the size of poverty in the examination region.

\section{Econometric analysis}

The Logit and Probit models have generally utilized models for dichotomous or dummy dependent variable. The Logit model expects cumulative logistic probability distribution. However, the Probit likelihood model is related to the cumulative normal probability function. The upside of these models over the direct likelihood model is that the probabilities are bound somewhere in the range of 0 and 1 (Gujarati, 2009).

Hosmer and Lemeshow (1989) have called attention to that the strategic circulation has preferences over the others in examining a dichotomous dependent variable. It is incredibly adaptable, moderately essential according to numerical perspective and fits a critical translation. So that to address the second destinations of the investigation Logit model was utilized. form:

The probability of being poor (an event occurring) as the

$$
\begin{gathered}
\operatorname{Pr}\left(y=\frac{1}{x}\right)=\operatorname{Pr}(Y=1)=\frac{e^{z i}}{1+e^{z i}}=\frac{1}{1+e^{-z i}} \\
Z=\beta_{0}+\beta_{1} x_{1}+\beta_{2} x_{2}+\cdots+\beta_{k} x_{k}+\varepsilon
\end{gathered}
$$


Table 2. Description of Explanatory Variables and their Hypothesized signs

\begin{tabular}{|c|c|c|c|}
\hline Variables & Independent Variables and its Measurement & Variable Type & Expected Sign \\
\hline SEX & Sex of the Family H.H. (if $\mathrm{M}=1, \mathrm{~F}=0$ ) & Dummy & Negative \\
\hline AGE & Age of the Family Head in year & Continuous & Positive \\
\hline FAMSZ & Family size of H.H. in an adult equivalent ratio & Discrete & Positive \\
\hline EDUC & $\begin{array}{l}\text { Education level of the } \mathrm{HH} \text { attain, where } 0=\text { unable to read and write; } 1=\text { grade } 1-4,2=\text { grade } 5 \text { - } \\
\qquad 8,3=\text { grade } 9-12,4=\text { above grade } 12\end{array}$ & Continuous & Negative \\
\hline DEPENR & $\begin{array}{l}\text { Dependency Ratio (dependent age below } 15 \text { plus and above 65) between } 15 \text { and } 64 \text { years } \\
\text { inclusive }\end{array}$ & Continuous & Positive \\
\hline LSZE & Land size of the household owned and measured in a hectare & Continuous & Negative \\
\hline OX & The number of oxen owned by the family & Continuous & Negative \\
\hline LTU & The number of Livestock holding by the family in TLU & Continuous & Negative \\
\hline USETECN & Households using technology (if Yes $=1$ other wise $=0$ ) & Dummy & Negative \\
\hline SAVING & Household participation in saving service (if Yes $=1$ other wise $=0$ ) & Dummy & Negative \\
\hline REMETT & The households' access to remittance & Dummy & Negative \\
\hline CREDIT & Households having access to credit service (if Yes=1 other wise=0) & Dummy & Negative \\
\hline EXTSN & Households getting the frequency of extension contact in a year (weekly, monthly and rarely) & Continuous & Negative \\
\hline OFFRM & Households having access to off-farm activity (if Yes $=1$ other wise $=0$ ) & Dummy & Negative \\
\hline HEALTH & Households having access to health service (if Yes=1 other wise=0) & Dummy & Negative \\
\hline
\end{tabular}

For a non-event (non-poor) cumulative logistic distribution, (1-pi) become as the form:

$$
1-\operatorname{Pr}(y=1 / x)=\frac{e^{-z i}}{1+e^{-z i}}
$$

Therefore, by dividing equation (1) by equation (2), we result with odds-ratio in binary response, which is as stated below:

$$
\frac{\operatorname{Pr}(y=1 / x)}{1-\operatorname{Pr}(y=1 / x)}=\frac{\operatorname{Pr}(Y=1)}{1-\operatorname{Pr}(y=1)}=\frac{\frac{1}{1+e^{-z i}}}{\frac{e^{-z i}}{1+e^{-z i}}}=\frac{1}{e^{-z i}}=e^{z i}
$$

Condition (4) is the odd-proportion for family falling underneath the neediness line. This is the proportion of the poverty that a family was poor to the likelihood that it was not poor. The natural logarithm of odd-proportion of condition (4) result was in logit model see as underneath.

$$
\begin{aligned}
L i=\ln \left(\frac{\operatorname{Pr}(Y=1)}{1-\operatorname{Pr}(y=1)}\right)=Z_{i}=Z \\
=\beta_{0}+\beta_{1} x_{1}+\beta_{2} x_{2}+\cdots+\beta_{15} x_{15}
\end{aligned}
$$

The parallel logit model for likelihood of being poor or non-poor and determinants of neediness as follows:

$$
\begin{aligned}
Y_{i}=\beta_{0}+\beta_{1} \text { Age } & +\beta_{2} \text { Sex }+\beta_{3} \text { Famsz }+\beta_{4} \text { Educ } \\
& +\beta_{5} \text { Depenr }+\beta_{6} \text { Lsze }+\beta_{7} \text { Ox } \\
& +\beta_{8} \text { TLU }+B_{9} \text { Extsn }+\beta_{10} \text { Remt } \\
& +\beta_{11} \text { Credit }+\beta_{12} \text { Tecnouse } \\
& +\beta_{13} \text { offrm }+\beta_{14} \text { Health } \\
& +\beta_{15} \text { Saving }+ \text { ci }
\end{aligned}
$$

Consequently, $\mathrm{Yi}=0$ if family unit is poor and $=1$ if family unit isn't poor, $\beta 0$ is regression boundaries, $\varepsilon i$ is the Error expression and the others are explanatory factors utilized in this examination.

\section{Description of the Variables Used in the Binary Logistic Model and Their Hypothesis}

The reliant variable of this examination was country family unit destitution. The reliant variable (y) is dichotomous or sham variable, which shows the likelihood of being poor for a family unit; where it spoke to (0) when it was poor and (1) when the families were non-poor.

\section{RESULT AND DISCUSSION}

The result and discussion of this section have included in three parts. The first section deals with the poverty line's derivation using the Cost of Basic Needs approach and aggregate poverty measurement using the poverty index. The second section deals with the descriptive statistics, and the third section focused on identifying rural household poverty determinants.

\section{Setting the Poverty line}

Following the methodology sections' steps, the study area's poverty line was established by the following form.

\section{Food poverty line}

$>$ Total Adult equivalent food Expenditure = 2,354,640.50Birr

$>25 \%$ Adult equivalent population food share = 56497.60Birr

$>$ Percentage Share of the lowest $25 \%$ population $=$ 0.02399415

$>$ Food poverty line $=3774.84$ Birr

\section{Non-food poverty line}

To obtain this line, we have divided the food poverty line by the food share of the lowest 25 per cent of the expenditure distribution.

Non-food poverty $=3774.84 / 2.399415=1573.233$ Birr.

Therefore, the Poverty line in the study area = food poverty line plus Non-food poverty line

\section{$=$ 3774.84Birr + 1573.233 Birr =5348.073Birr}

Based on this poverty line, out of 152 households, 60 households (39.47) per cent were poor, and 92 households (60.53) per cent were identified as non-poor.

\section{Measures of Poverty}

Using the poverty as mentioned earlier line based on the total expenditure necessary for measuring aggregate poverty. The incidence of poverty (headcount index) shows that 39.47 
Table 3. FGT measure of Poverty status of five surveyed Kebeles

\begin{tabular}{cccccccc}
\hline Kebeles & Poor & Non-poor & Total & \% share of poor & $\mathbf{P}_{\mathbf{0}}$ & $\mathbf{P}_{\mathbf{1}}$ & $\mathbf{P}_{\mathbf{2}}$ \\
\hline Zala Shasha & 14 & 19 & 33 & 23.3 & 0.4242 & 0.1250 & 0.0521 \\
\hline Gulgula & 9 & 14 & 23 & 15 & 0.3913 & 0.1029 & 0.0413 \\
\hline W/Busha & 22 & 30 & 52 & 17 & 0.4231 & 0.1216 & 0.0518 \\
\hline Waja Shoya & 5 & 12 & 17 & 27 & 16.7 & 0.2941 & 0.0867 \\
\hline K/Godera & 10 & $\mathbf{6 0}$ & $\mathbf{9 2}$ & $\mathbf{1 5 2}$ & $\mathbf{1 0 0}$ & $\mathbf{0 . 3 9 4 7}$ & 0.0291 \\
\hline Total & $\mathbf{6 0 . 1 0 3 5}$ & $\mathbf{0 . 0 4 2 7}$ \\
\hline
\end{tabular}

Source: Own computed from survey data, 2019

Table 4. Mean of Rural Household Poverty

\begin{tabular}{|c|c|c|c|c|c|c|c|}
\hline \multirow[t]{2}{*}{ Variables } & \multicolumn{2}{|c|}{ Poor $(n=60)$} & \multicolumn{2}{|c|}{ Non-poor $(n=92)$} & \multicolumn{2}{|c|}{ Total $(n=152)$} & \multirow{2}{*}{$t$-value } \\
\hline & Mean & SD & Mean & SD & Mean & SD & \\
\hline Age & 57.45 & 9.71 & 43.21 & 8.21 & 48.83 & 11.24 & $53.564^{* * * * *}$ \\
\hline Family size & 7.55 & 2.17 & 5.01 & 1.15 & 6.01 & 2.046 & $36.238 * * *$ \\
\hline Depend. Ratio & 1.05 & 0.62 & 0.70 & 0.39 & 0.84 & 0.52 & 19.727 ***** \\
\hline Land size & 0.49 & 0.45 & 0.75 & 0.66 & 0.65 & 0.60 & $13.280^{* * * * *}$ \\
\hline Oxen owned & 0.35 & 0.48 & 1.08 & 0.65 & 0.79 & 0.69 & $14.168^{* * * *}$ \\
\hline TLU & 1.76 & 0.58 & 3.77 & 1.05 & 2.98 & 1.33 & $27.614^{* * * *}$ \\
\hline
\end{tabular}

Note $* * * *$ Significant at less than $1 \%$ probability level;

Source: Own survey result, 2019

Table 5. Proportion of Rural Household Poverty

\begin{tabular}{|c|c|c|c|c|c|}
\hline Variables & Categories & Poor (\%) & Non-poor (\%) & Total (\%) & $\chi^{2}$-value \\
\hline \multirow{2}{*}{ Sex } & Male & 73.3 & 85.9 & 80.9 & \multirow{2}{*}{$3.697 *$} \\
\hline & Female & 26.7 & 14.1 & 19.1 & \\
\hline \multirow{4}{*}{ Education } & Unable to read and write & 33.3 & 14.1 & 21.7 & \multirow{4}{*}{$35.521 * * *$} \\
\hline & $1-4$ & 31.7 & 27.2 & 28.9 & \\
\hline & $5-8$ & 25 & 35.9 & 31.6 & \\
\hline & $9-12$ & 10 & 22.8 & 17.8 & \\
\hline \multirow{2}{*}{ Remittance } & Yes & 41.7 & 55.4 & 50 & \multirow{2}{*}{$2.754^{*}$} \\
\hline & No & 58.3 & 44.6 & 50 & \\
\hline \multirow{3}{*}{ Extension } & Weekly & 23.3 & 48.9 & 38.8 & \multirow{3}{*}{$13.305 * * *$} \\
\hline & Monthly & 28.3 & 28.3 & 28.3 & \\
\hline & Sometimes & 48.4 & 22.8 & 32.9 & \\
\hline \multirow{2}{*}{ Use of technology } & User & 56.7 & 76.1 & 68.4 & \multirow{2}{*}{$6.339^{* * *}$} \\
\hline & Non-user & 43.3 & 23.9 & 31.6 & \\
\hline Health centre & User & 41.7 & 84.8 & 67.8 & $30.905^{* * * *}$ \\
\hline
\end{tabular}

Note: *******, and * Significant at less than $1 \%, 5 \%$ and $10 \%$ probability level respectively.

Source: Own survey result, 2019

per cent of the sampled households in the study cannot afford the essential calorie requirement per day and deemed below the poverty line.

The poverty gap (consumption shortfall) of poor to reach the poverty line in is 10.35 per cent, and poverty severity index shows that 4.27 per cent variation among poor households in the study area.

\section{Descriptive Analysis}

\section{Demographic factor of the households}

The segment attributes of family units demonstrated that the absolute examined family unit heads ran from 26 up to76 years, and the general mean age esteem is 48.83 years. The time of low-income family heads went from 32 as long as 76 years having the mean age estimation of 57.45 years while the non-poor family unit heads ran from 26 up to 62 with the mean age estimation of 43.21 years. The finding uncovered that the average family size was 6.01 , which are higher than the average family size of Wolaita Zone 5.1 (CSA, 2007). The t-test result shows a significant mean distinction among poor and nonpoor family units for age, family unit size, and reliance proportion (Table 4).

The mean cultivated land size of poor, non-poor and all families was $0.49,0.75$ and 0.65 hectares. The t-test result estimation shows significant mean distinction among poor and non-poor family units at under $1 \%$ likelihood level $(\mathrm{t}=$ 13.280; $p=0.000$ ) (Table 4). Along these lines, bigger farm landholder would be less poor than those with the little land proprietor, because of the way that, the bigger landowner has related with higher chance to create more food. It is the most significant resource for ranchers, and their employment relies predominantly upon it.

Table 5 demonstrates a chi-square test for discrete factors theorized to influence provincial family unit destitution. About $80.9 \%$ were male-headed family units from the complete sampled families, and $19.1 \%$ were female-headed families. Out of whole male-headed families, $35.8 \%$ have found to be poor, and $64.2 \%$ were non-poor. Out of all-out 
Table 6. Logistics of Determinants of Rural Household-level Poverty Status

\begin{tabular}{|c|c|c|c|c|c|}
\hline Independent variables & B & S.E. & Wald & $\operatorname{Exp}(B)$ & Sig. \\
\hline Sex & -4.045 & 2.095 & 3.726 & 0.018 & $0.054 *$ \\
\hline Age & -0.228 & 0.119 & 3.681 & 0.796 & $0.055^{*}$ \\
\hline Family size & 2.062 & 1.003 & 4.229 & 7.865 & $0.04^{* * *}$ \\
\hline Educational level & -0.898 & 0.330 & 7.405 & 0.454 & $0.007^{* * * * * * 1 \%}$ \\
\hline Dependency ratio & -2.828 & 1.862 & 2.307 & 0.059 & 0.129 \\
\hline Land size & -5.864 & 2.130 & 7.579 & 0.003 & $0.006^{* * * *}$ \\
\hline Oxen & -0.626 & 1.443 & 0.188 & 0.869 & 0.665 \\
\hline TLU & -2.515 & 0.883 & 8.112 & 0.081 & $0.004^{* * * *}$ \\
\hline Remittance access & -2.104 & 1.651 & 1.625 & 0.122 & 0.202 \\
\hline Credit access & -0.205 & 1.105 & 0.034 & 0.815 & 0.853 \\
\hline Use of technology & -3.628 & 1.927 & 3.546 & 0.025 & $0.060^{*}$ \\
\hline Off-farm activity & -1.808 & 1.263 & 2.049 & 0.164 & 0.152 \\
\hline Extension contact & -0.440 & 0.875 & 0.252 & 0.552 & 0.615 \\
\hline Health center access & 2.412 & 1.828 & 1.740 & 11.154 & 0.187 \\
\hline Saving participation & -3.020 & 1.709 & 3.124 & 0.049 & $0.077 *$ \\
\hline Constant & -21.790 & 9.569 & 5.186 & 0.000 & 0.023 \\
\hline-2 Log likelihood & & & 31.487 & & \\
\hline Model Chi-Square $\left(\chi^{2}\right)$ & & & $172.442 * * * *$ & & \\
\hline Correct prediction of all samples (count $\left.\mathrm{R}^{2}\right)(\%)$ & & & 94.1 & & \\
\hline Sensitivity/ Correct prediction of non-poor (\%) & & & 95.7 & & \\
\hline Specificity/ Correct prediction of poor (\%) & & & 91.7 & & \\
\hline
\end{tabular}

Note: ******, and * Significant at less than $1 \%, 5 \%$ and $10 \%$ probability level respectively.

Source: Model output, 2019

female-headed families, $55.2 \%$ were discovered to be poor, and $44.8 \%$ were non-poor. It demonstrates destitution rates are high in female-headed families than male-headed family units. This could be because of the nearness of women's oppression in the work market, and they have denied the chances of practising when contrasted with males in numerous angles.

In light of the examination result, the family heads' educational background was $21.7 \%, 28.9 \%, 31.6 \%$, and $17.8 \%$ incapable of perusing and composing, grade $1-4$, grade $5-8$, and grade 9-12, separately. The chi-square test shows that poor people and non-poor had huge relationship at under $1 \%$ likelihood level $(\chi 2=32.521 ; \mathrm{p}=0.001) \quad$ (Table 5). It demonstrates when people's education level builds their degree of getting, ability, and so on increments and works can get work with great pay, conduct businesses and any financial exercises dependent on the sufficiently beneficial knowledge besides, resource utilization of educated households and diversifying their livelihood options to overcome rural poverty.

\section{Econometric Analysis}

The explanatory variables were tested for the existence of a multi-linearity problem using Variance Inflation Factor (VIF) for Continuous explanatory variables and the contingency coefficient for Dummy variables before putting them into the model. Accordingly, the test shows that there is no sever colinearity problem among the variables under investigation.

The goodness-of-fit measurements of the model were also given in Table 6 . The computed log-likelihood ratio statistics (Chi-square) exceed the Chi-square critical values at 1 per cent significance level, confirming that the independent variables taken together influence the determinants of rural household poverty. Another goodness of fit measurement is computing the number of correct predictions to the complete number of observations for both poor and non-poor to find the number of correctly predicted observations. The method is based on the principle that if the event's estimated probability is less than 0.5 , the event will not occur and if it is more significant than 0.5 , the event will occur. The result shows that the logistic regression model correctly predicted about 91.7 per cent and 95.7 per cent for poor and non-poor, respectively (Table 6). The higher estimation of the sensitivity estimations shows the better classification of the events using the specified model. Furthermore, the model outcome shows the accurately anticipated per cent of all inspected family unit were $94.1 \%$, which is more noteworthy than 0.50 demonstrated that the model had fitted the information quite well.

The logistic regression model's estimated coefficients show that eight were significant out of the fifteen factors hypothesized to distinguish rural family unit poverty determinants. Simultaneously, the rest of seven was not critical in clarifying the varieties of the dependent variable. The significant variables were, for example, sex of family head, age of family head, family size, educational level, land size, total livestock unit, use of technology and saving participation was a significant effect on the determinants of rural household poverty (Table 6).

Sex of the Household head (SEX) was huge at under 10\% likelihood level and showed a negative relationship with rustic neediness. That implies holding different factors consistent; when the family head was male, the log chances of falling into neediness diminishes by a factor of 0.018 occasions lower than their partners. The conceivable clarification of this outcome was that female-headed families have a higher probability of falling into neediness than their male partners. It can be contemplated out that male family heads better participate in any productive activities than female heads. This finding was following the comparative investigation directed by Firew (2017). It found that female-headed families have lower 
admittance to gainful assets and social administrations, which influences their beneficial capacity and their intrafamily unit allotment of assets.

Age of the Household head (AGE) was huge at under 10\% likelihood level and showed a negative relationship in clarifying the rustic family level destitution. It implies, as the age of the Household Head increments by a solitary year, keeping different variables stays steady. The probability of the families being non-poor decreases by an odd log ratio of 0.796 . This shows the family unit heads who are at the scope of dynamic working-age participate in various off-farm activities and net income to improve their family riches status. As Lekobane et al. (2017) indicated on their work of determinants of family welfare and poverty, the family head's age significantly impacts a family's ability to manage and distribute resources for all its members. Therefore, this finding was steady with the discovery of Lekobane et al. (2017).

Family size in Adult Equivalent (FAMLSZ): The family size in adult equivalent was decidedly related to rural poverty, and the coefficient is measurably critical at under 5 per cent likelihood level. Keeping others factors consistent, a family size increments by one adult equivalent individual, the likelihood of a family unit falling into poverty increments by an odd log proportion of 7.685. Therefore, large family sizes result in a high fertility rate in rural areas, less employment opportunity, weak off-farm income participation, family members become unemployed, decreased savings, and low payment rate. This finding was consistent with similar studies conducted on rural poverty. According to Nega (2015), in his analysis of rural poverty determinants and dimensions, as family size expands, there is no admittance to have more land for development to satisfy the need for enormous family size. The per-capita land size fall makes more weight on food utilization and bothers the opportunity of being falling into poverty. Tadelech (2018) indicated in her investigation of the rural poverty determinants and weakness, an expansion in family size outcomes in diminishing per capita salary and diminishing per-capita reserve funds. Accordingly, having more family unit size disturbs the opportunity of falling into rural poverty.

Education of Household head (EDUC): The family unit head's education coefficient was negative and measurably noteworthy at less than 1 per cent probability level. The odds ratio for the variable suggests that, holding other variables constant, when education level of the family head increments by a unit, the likelihood of a family falling into poverty diminishes by an odd log proportion of 0.454 . Similar studies conducted on poverty by Moges (2013) and Mohammed (2017), confirms these findings. They found that when peoples' education level increases their understanding, skill, and labours, they can get work with an excellent salary, conduct businesses, and any economic activities dependent on product knowledge.

Household's Land size in hectare (LSZE): It is generally expected that the cultivable land size coefficient had contrarily related and measurably noteworthy at less than $1 \%$ likelihood level, implying that land size shows a negative relationship with the rustic family poverty status. The suggestion is that the probabilities of being non-poor increases with farm size. Households with larger sizes tend to be highly produced than those with littler sizes, and the other way around. This is perhaps because the size of landholding is an intermediary for a large group of elements including riches, access to credit, and the ability to bear risk and income. Bigger farmlands are related with more prominent richer and income and expanded accessibility of capital, which increment the likelihood of interest in acquiring homestead inputs that expand food creation and get away from absolute poverty. One could see that more superior efficiencies in the utilization of farm assets than the smallholding farms. The smallness of land possessions diminishes various current agrarian contributions because of the absence of buying power in small farmers' possession. It shows a family's capacity to produce adequate monetary business relies upon the farming area. The chances proportion for the variable suggests that holding different factors consistent, expanding one area of developed land, and the likelihood of family falling into neediness diminishes by an odd log proportion of 0.003 . This finding was predictable with the comparative investigation led by Borko (2017), says that pay and utilization may go up for a rustic family unit as landholding has expanded. This shows a family's capacity to produce adequate monetary occupation relies upon the earth where the land exists for rural use.

Livestock Ownership (TLU): The coefficient of the whole livestock unit had contrarily related and measurably critical at under $1 \%$ likelihood level. The rationale behind it is that families who have huge herd size had higher probabilities of getting away from neediness since they can procure more income from livestock animals creation and get a chance to consume animal products. As livestock ownership of the household increases by a unit (one TLU), the family's likelihood of falling into poverty decline by an odd log proportion of 0.081 , when other factors stay constant. This finding was steady with the close examination done by Moges (2013) and Afera (2015), found that livestock animals possession expands the income of the rural household. This empowers them to buy food when they are short of their stock and put resources into the acquisition of homestead inputs that expand food creation and their family sustenance.

Use of Technology (USETCNLGY): Use of various farming innovation was adversely related and measurably noteworthy at fewer than 10\% likelihood level. Family units utilizing distinctive agrarian design have better opportunities to get more yields per hectare and more pay which lifted them above the destitution line. The employments of various agricultural innovation have discrete changes from 0 to 1 (no utilization to utilize), the likelihood of getting away from destitution increments by an odd log proportion of 0.025 ; expecting different things were held steady. This finding was predictable with the discoveries of Girma and Temesgen (2017).

Saving Participation of the Household (SAVING): The saving participation was contrarily associated with rural family-level poverty and statistically significant at less than $10 \%$ likelihood level. This outcome suggests that family units' saving paring cooperation increments from 0 to 1 , the likelihood of falling into poverty decline by an odd log proportion of 0.049 , keeping different factors consistent. This finding was reliable with a comparative investigation on rustic destitution in southern Ethiopia directed by Tadelech (2018). It shows that families with saving have a better opportunity to 
escape from poverty since they have significant ground to contribute to beneficial organizations and adapt momentary market stuns. At the individual level, sparing assists families with smoothing utilization and profitable limit.

\section{CONCLUSION AND RECOMMENDATIONS}

\section{Conclusion}

Poverty is one of the central issues and the most certain social problems on the planet. It has no geological limit and multidimensional. Along these lines, this examination was led to distinguish determinants of rural household poverty in Sodo Zuria Woreda, Woliata Zone, Ethiopia. The survey data were gathered from 152 sampled households from five Kebeles.

The investigation utilized the Cost of Basic Needs technique to process the poverty line and FGT strategy to quantify the examination zone's total poverty index. Thus, $39.47 \%$ of the Woreda family unit was discovered to be poor among the examined families. The absolute poverty line for the study area was 5348.073 Birr every year per adult identical. The poverty gap in the examination zone was $10.35 \%$ of the poverty line which implies the average total consumption expected to bring the whole poor family units at any rate at this poverty line was $10.35 \%$ of the poverty line. The gauge of the seriousness of poverty among the rustic poor was $4.27 \%$ this suggests there was 4.27 per cent of relative material hardship among poor families.

The most significant probability evaluations of the logistic regression model show that many fifteen explanatory factors (seven continuous and eight dummy) factors were remembered for the model. The Binary logistic model assessment uncovered that eight explanatory factors were statistically significant to under $10 \%$ likelihood level. In comparison, the staying seven factors were not significant in explaining variations of the dependent variable. The critical factors were, for example, sex of family head, age of household head, family size, educational level, land size, total livestock unit, use of technology and saving participation was significant effect rural household poverty status. Family size was positively correlated with households' poverty status, whereas, the rest were inversely related to rural household poverty status.

The investigation discovers that agribusiness keeps assuming a prevailing function in the examination zone's livelihoods and income source. The smaller landholding size was related to huge family size and population growth, causing the deficiency and shortage of cultivable land. This makes more weight on scant land. It consequently disturbs youth migration from the region and the progressive loss of land productivity, especially depletion of soil fertility. Henceforth, the low yield and low efficiency of agricultural production increment the issue of rural household poverty.

\section{Recommendations}

The study's findings are the survey data results highlighted; the following recommendations are forwarded as substitutes for reducing rural poverty in general and particularly for Sodo Zuria Woreda.
- Female household head has a higher probability of falling into poverty than the male household head. Their level of literacy and involvement in economic and social activities are low compared to their counterpart. Hence, educating women and creating a conducive environment for their participation in social and economic activities and empowering women is one of the remedial measures to reduce poverty in the research area.

- Age has found to be the determining factor of poverty in the research area. The result implies that age increases the household's productive capacity decreases, and the individual becomes a few savings. Therefore, governmental or local agencies that would like to support aged households in the examination area.

- The study found that family size was positively and significantly associated with rural poverty. This calls for improving family organizing and strengthening of the Integrated Health Extension Package program in the assessment area. As needs be, despite home to home care appearances on family masterminding open discussions about how to use safeguard systems ought to be realized in more sifted through route than beforehand. The acute effects on women's prosperity, work power backing, and productivity could also decrease dependence and dejection.

- Land size in hectares was one of the determinants of rural household level poverty in the study area. As land is the essential asset for the farmers, effective utilization of it improves its productivity. For the shortage of land, policymakers need to focus on improving land fertility for reducing poverty in the study area.

- Educational background of household head was the other determinants of rural poverty. Education broadens humans' thinking capacity and improves welfare; hence, strengthening primary, secondary, and higher education and vocational training is better in reducing poverty status in the study area.

- Livestock is the leading means of agricultural production and one of the significant explanatory variables. As far as the rural household has been leading non-mechanized agriculture based on livestock farming, attention should be given to asset-building programs and credit programs, emphasising livestock production.

- Using of innovation was additionally adversely related to neediness in the investigation territory. Utilization of innovation assumes a noteworthy part in expanding creation and boosting agricultural profitability, and that offers a chance to be engaged with salary producing exercises. It determines the high efficiency of the family unit to escape from neediness. Therefore, governmental bodies and NGOs should be introduced and create awareness on using new agricultural technology options.

- Participation in saving is also one of the determining factors of poverty. Saving is crucial for individual and 
societal welfare. Savings help households in smoothening consumption and finance productive investments in human and business capital. Therefore, awareness creation for participating in any formal or informal saving institution was critical for reducing rural poverty in shock seasons.

- Poverty reduction strategies should target specific locations and specific households as most of the time poverty by its nature is individual-centred rather than aggregate. Therefore, schemes that can improve incomes of individual households and certain localities should be employed selectively. Furthermore, there ought to be joint exertion in identifying the causes, outcomes, and duties in the Government's execution.

- Finally, poverty is not only the problem of Sodo Zuria Woreda; instead, it is a problem for the country. Therefore, the poor themselves, Government, NGO, and other stakeholders should strengthen their participation to reduce poverty.

\section{ETHIOPIA TECHNICAL TERMS}

\section{Dega: Highland altitude}

Kolla: Lowland mainly lower than $500 \mathrm{~m}$ above sea level.

Woyne Dega: Mid Highland altitude

Kebele: A sort of authoritative division at the lower level which is higher than the town. The term Kebele signifies "Village" in Ethiopian language. The Kebele is the fundamental regulatory unit of the Ethiopian Government.

Woreda is called as "District". Local administrative above Kebele level which is equivalent of a District.

Author contributions: All co-authors have involved in all stages of this study while preparing the final version. They all agree with the results and conclusions.

Funding: No external funding is received for this article.

Declaration of interest: The authors declare that they have no competing interests.

Ethics approval and consent to participate: Not applicable.

Availability of data and materials: All data generated or analyzed during this study are available for sharing when appropriate request is directed to corresponding author.

\section{REFERENCES}

ADBG (African Development Bank Group). (2015). Concepts and Measurement of vulnerability to poverty and other issues: A review of the literature. SSRN. https://doi.org/10.2139/ssrn.2893054

Afera, N. (2015). Determinants of poverty in rural poverty in Tigray, Ethiopia. Evidence from rural households.

Babbie, E. (1995). The Practice of Social Research (7th Ed.). Wadsworth Publishing Company, Belmont, California. 101 pp.
Borko, Z. P. (2017). Determinants of poverty in Damot Gale, households analysis (M.Sc. Thesis), Wolaita Sodo University, Ethiopia.

CSA. (2007). Population and Housing Census of Ethiopia, Addis Ababa, Ethiopia.

CSA. (2015/16). Household consumption and Expenditure survey. Addis Ababa, Ethiopia.

CSA. (2017). Agricultural Sample Survey. Addis Ababa, Ethiopia.

Foster, J., Greer, J. L. and Thorbecke (1984). A class of Decomposable Poverty Measures. Econometrica, 52(3), 761766. https://doi.org/10.2307/1913475

Girma, M. and Temesgen, Y. (2017). Determinants and its extent of Rural poverty in Ethiopia: Evidence from Doyogena District, Southern part of Ethiopia. Journal of Economics and International Finance, 10(3), 22-29. https://doi.org/ 10.5897/jeif2017.0837

Gujarai, D. N. (2009). Basic Econometrics (5 $5^{\text {th }}$ Ed.). New York: The McGraw-Hill, Inc.

Hosmer, D. W. and Lemeshow, S. (1989). Applied logistics regression. New York: A Wiley-Inter science publication.

Khan, M. H. (2010). Rural poverty in developing countries implications for public policy. IMF (International Monetary Fund).

Lekobane R. and Selekob, (2017). Determinants of household welfare and poverty in Botswana.

Moges, A.G. (2013). The Challenges and policies of poverty reduction in Ethiopia include special issues in the Ethiopian Economic Institute humanities and social science, University of Tsukuba, Japan. Ethiopian E-journal for Research and Innovation Foresight, Vol. 5, No.1 (2013) Pp. (94-11).

Mohammed, M. B. (2017). Measure and Determinants of Urban poverty in the case of the Southern Nation, Nationalities and People Region (SNNPR), Ethiopia. International Journal of Scientific and Research Publications, 7(3), 181-189.

Motta, F. M. (2017). Determinants of Urban poverty in Sodo Town (M.Sc. Thesis), Wolaita Sodo University, Ethiopia.

Nakachew Negash Nafako. (2018). Determinants of rural poverty in Duguna Fango Woreda, Wolaita Zone (M.Sc. Thesis), Wolaita Sodo University, Ethiopia

Sodo Zuria Woreda Agriculture and Natural Resource Development Office. (2018). Woreda Land Administration annual data.

Sodo Zuria Woreda Finance and Economic Development Office. (2018). Annual Socio-economic report.

Tadelech Tesgaw. (2018). Determinants of rural poverty and vulnerability to poverty in Wollo, Amhara Region (M.Sc. Thesis), Wolaita Sodo University, Ethiopia.

Tiruneh, E. A. (2006). Determinants of Urban poverty in Debre Markos Town. A household-level analysis (M.Sc. Thesis). Addis Ababa University, Ethiopia.

Yamane, T. (1967). Statistics and introductory analysis (2nd Ed.) New York: Harper and Row. 